\title{
Best practice recommendations for the use of external telemetry devices on pinnipeds
}

\author{
Markus Horning ${ }^{1,2^{*}}$ D, Russel D. Andrews ${ }^{3}$, Amanda M. Bishop ${ }^{1}$, Peter L. Boveng ${ }^{4}$, Daniel P. Costa ${ }^{5}$, \\ Daniel E. Crocker ${ }^{6}$, Martin Haulena', Mark Hindell ${ }^{8}$, Allyson G. Hindle ${ }^{9}$, Rachel R. Holser ${ }^{5}$, Sascha K. Hooker ${ }^{10}$, \\ Luis A. Hückstädt', Shawn Johnson ${ }^{11}$, Mary-Anne Lea ${ }^{8}$, Birgitte I. McDonald ${ }^{12}$, Clive R. McMahon ${ }^{8,13}$, \\ Patrick W. Robinson ${ }^{5}$, Renae L. Sattler ${ }^{1}$, Courtney R. Shuert ${ }^{14}$, Sheanna M. Steingass ${ }^{15}$, Dave Thompson ${ }^{10}$, \\ Pamela A. Tuomi ${ }^{1}$, Cassondra L. Williams ${ }^{16}$ and Jamie N. Womble ${ }^{17}$
}

\begin{abstract}
Pinnipeds spend large portions of their lives at sea, submerged, or hauled-out on land, often on remote off-shore islands. This fundamentally limits access by researchers to critical parts of pinniped life history and has spurred the development and implementation of a variety of externally attached telemetry devices (ETDs) to collect information about movement patterns, physiology and ecology of marine animals when they cannot be directly observed. ETDs are less invasive and easier to apply than implanted internal devices, making them more widely used. However, ETDs have limited retention times and their use may result in negative short- and long-term consequences including capture myopathy, impacts to energetics, behavior, and entanglement risk. We identify 15 best practice recommendations for the use of ETDs with pinnipeds that address experimental justification, animal capture, tag design, tag attachment, effects assessments, preparation, and reporting. Continued improvement of best practices is critical within the framework of the Three Rs (Reduction, Refinement, Replacement); these best practice recommendations provide current guidance to mitigate known potential negative outcomes for individuals and local populations. These recommendations were developed specifically for pinnipeds; however, they may also be applicable to studies of other marine taxa. We conclude with four desired future directions for the use of ETDs in technology development, validation studies, experimental designs and data sharing.
\end{abstract}

Keywords: Biotelemetry, Biologging, Tagging, Tracking, Marine mammal, Pinniped, Animal welfare, Reduction, Refinement, Replacement

\section{Introduction}

Externally affixed telemetry devices (ETDs) have been used very effectively to monitor movement, behavior and physiology of highly mobile vertebrates since the 1960s [21, 50, 59, 71]. This approach has been especially useful for marine vertebrates-pinnipeds in particular-that often spend a considerable amount of time in remote locations or submerged [44, 53, 63, 78]. Initial device designs were relatively large, and used mechanical or opto-mechanical transducers and recording media.

\footnotetext{
*Correspondence: markush@alaskasealife.org

1 Alaska SeaLife Center, 301 Railway Avenue, Seward, AK 99664-1329, USA

Full list of author information is available at the end of the article
}

The original 'Kooyman' Time-Depth Recorder (TDR) was based on a modified, 60-min wind-up kitchen timer integrated with a Bourdon tube pressure transducer connected to a stylus that scratched into smoked glass. This entire assembly was encased in a pressure housing, and with a mass of $1.5 \mathrm{~kg}$, it could only be used on very large animals, such as Weddell seals (Leptonychotes weddellii) [58]. The next-generation TDRs developed by J. Billups (Meer Instruments, Palomar Mountain, CA, USA) used photographic film as a medium rotated by a batterydriven motor inside of a 20 -cm-long tubular housing of $5.3-\mathrm{cm}$ diameter, reducing the total mass to $0.5 \mathrm{~kg}$ [37], Fig. 1a). This allowed for use on smaller pinnipeds, such as Galápagos fur seals (Arctocephalus galápagoensis). The 


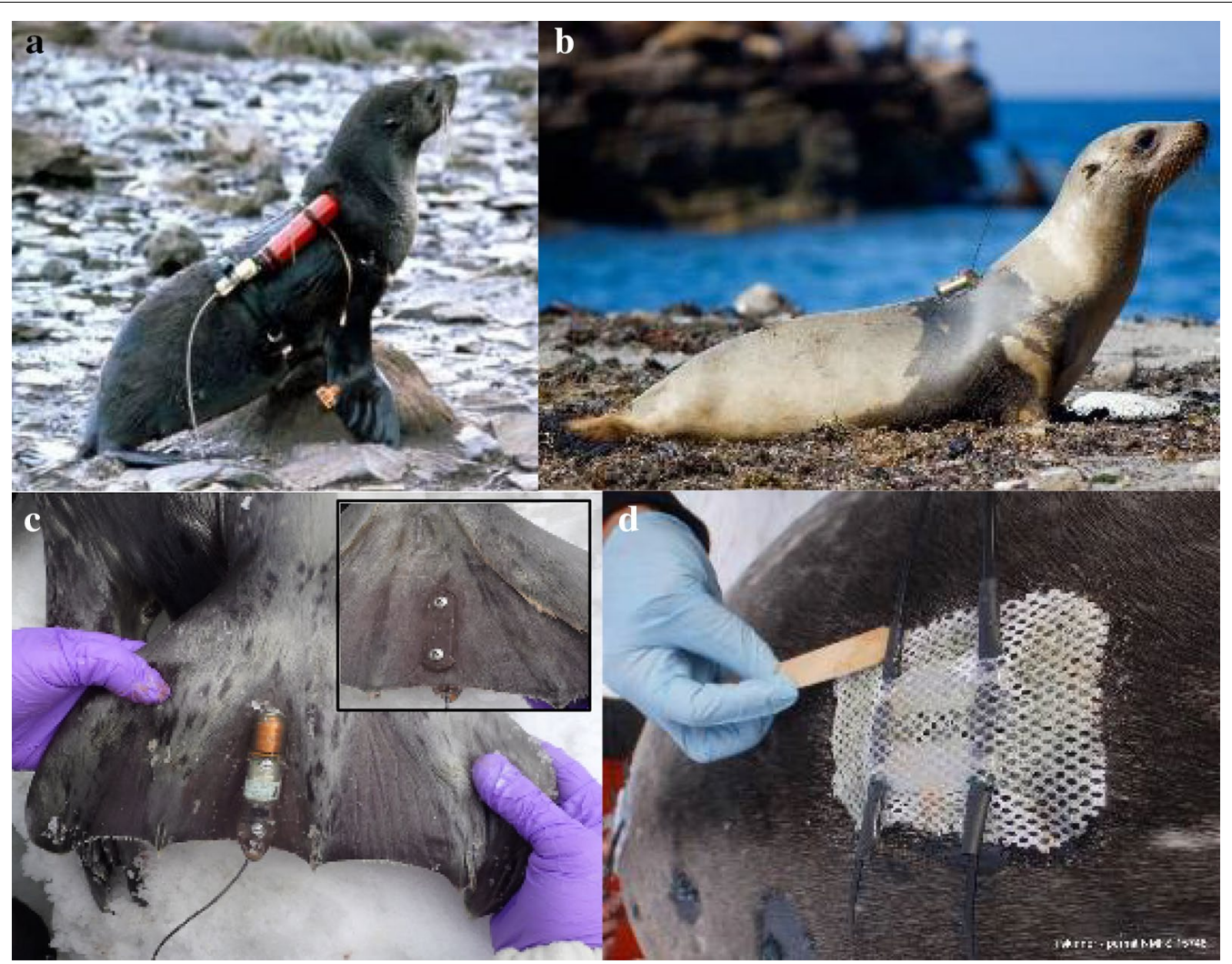

Fig. 1 Examples of improvements in ETD attachment methods over time. The attachment methods allow different placements and attachment durations, and may have different impacts on study animals (Recommendations \# 9 and 10). a Adult female Antarctic fur seal on Bird Island, South Georgia. The female is carrying an opto-mechanical depth recorder (Meer Instruments, Palomar Mountain, CA, USA; red cylinder, $210 \times 50$ mm, $700 \mathrm{~g}$ ) and a VHF beacon (Telonics Inc., Mesa, AZ, USA, clear epoxy cylinder, approx. $100 \times 30 \mathrm{~mm}, 100 \mathrm{~g}$ ) that are attached using a harness of nylon webbing worn by the animal, illustrating older tag technology and attachment methods. This was one of the early investigations into pinniped diving behavior and its relationship to prey distribution from the late 1970s through the mid 1980s [23]. Photo @ DP Costa, 1983. b Juvenile California sea lion at Año Nuevo Island in 2016, instrumented with a SPOT6 Argos transmitter $(72 \times 54 \times 24 \mathrm{~mm}, 119 \mathrm{~g}$, Wildlife Computers) attached with Loctite Quickset ${ }^{\mathrm{TM}}$ 10-min, 2-component Epoxy (Product \# IDH1289278, Henkel Corp., Düsseldorf, Germany). This epoxy cures within about 8-12 min at ambient temperatures between 10 and $18^{\circ} \mathrm{C}$, while generating comparably little reaction heat if sufficiently thin layers are used. Care needs to be taken with larger devices that may trap reaction heat between fur and tag. In warmer temperatures, frozen gel-packs can be used to slow reaction and cool epoxy and tags (Recommendation \# 10). The back-mounted attachment shown here typically results in fewer Argos uplinks at sea, and lower quality location estimates, than head-mounted transmitters shown in Figs. 3b and $5 \mathrm{~b}$. This animal was part of a study examining the movement and diving behavior of juvenile California sea lions, an age class about which very little is known due to their transient state and the resulting difficulty in recapturing them [77]. These animals were instrumented opportunistically during handling for a project studying the occurrence Leptospirosis in the Año Nuevo population (Recommendations \# 5 and 6). The wet pelage across the shoulders and fore-flippers is from water and ice used to keep the animal cool (Recommendation \# 7) and slow exothermic epoxy curing. Photo $\odot$ PW Robinson, 2015, NMFS Permit \#17952. c Dorsal and plantar (inset) views of a SPOT Argos transmitter (Wildlife Computers) attached to the interdigital webbing on the hind-flipper of a spotted seal. Photos @ PL Boveng, 2016, NMFS Permit \#19309. d Nylon mesh is superficially glued to the fur of an adult Weddell seal using Devcon type 14265 5-minute two-component epoxy (ITW Performance Polymers, Chicago, IL, USA), study details are given in [49]. In the study area in McMurdo Sound, no natural predators are present to possibly cue in on increased visibility that could result from the white patch. In areas with predators, dark mesh should be used. The Devcon epoxy is quicker setting than the Loctite Quickset epoxy referenced in Panel B, making it more suitable in colder climates. At lower temperatures, providing additional heat via hot-packs (e.g., snap to heat gel packs) may be required to enable curing. Otherwise epoxy may simply freeze, giving the appearance of curing, but without adhering power. Channels formed from heat shrink tubing allow the subsequent attachment of ETDs via plastic or metal zip ties. This method allows for easy device removal by cutting ties, and the mesh base remains on the animal and is shed during the annual molt. Plastic ties work well in temperate climates, but become brittle in cold climates where metal ties provide more secure tag retention. For stainless steel ties, using retained-tension ties prevents loosening that occurs in standard ball-lock metal ties on rigid backing. Some researchers wrap tags in self-fusing rubber splicing tape (e.g., 3-M Temflex ${ }^{\mathrm{TM}}$ type 2155) that can

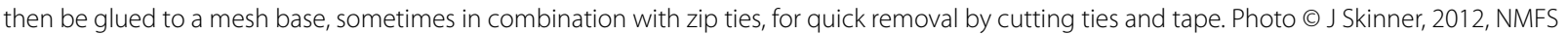
Permit \#15748 

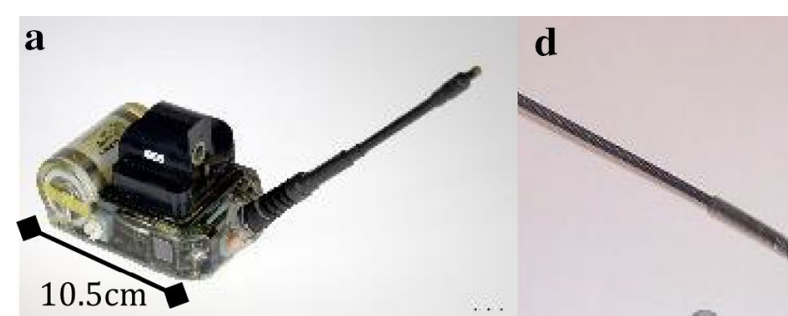

b

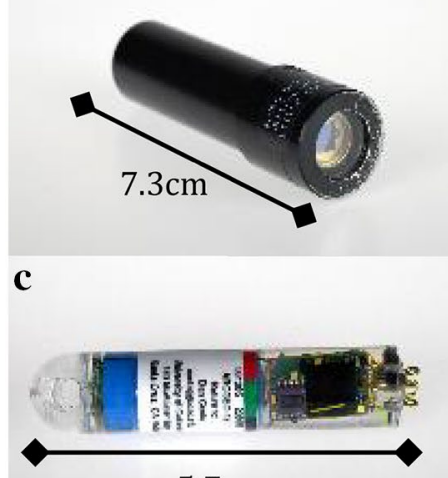

$5.7 \mathrm{~cm}$

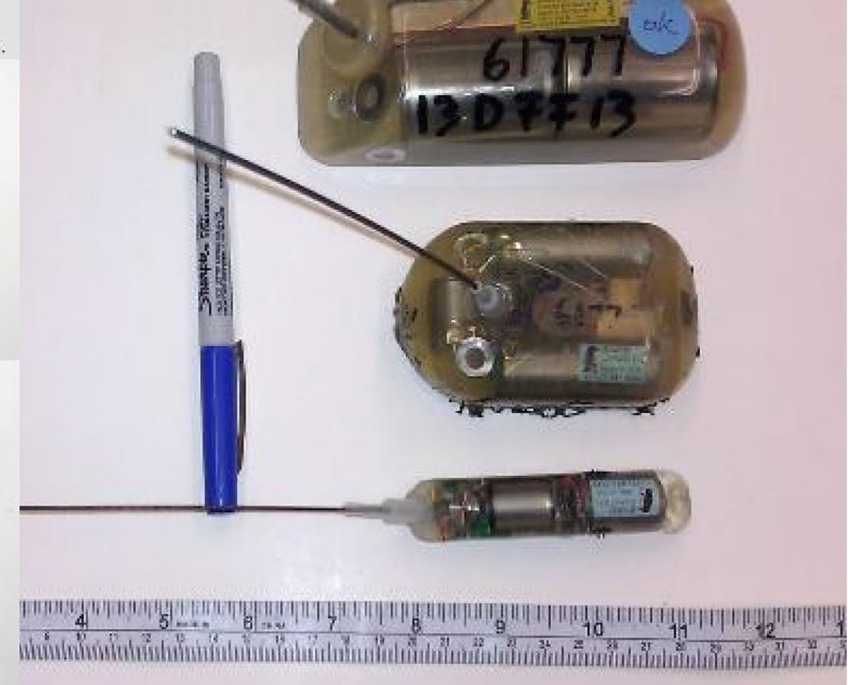

Fig. 2 Examples of recent and contemporary ETDs. a CTD-SRDL archival Argos transmitter configured with CTD and Fluorometry sensors (SMRU Instrumentation, St. Andrews, United Kingdom; $105 \times 72 \times 60$ mm, 630 g). Mid-2000s to present. Photo $\odot$ by DP Costa. b Archival data logger with tri-axial jaw accelerometer and light level sensor designed for detecting bioluminescence (Little Leonardo Corp., Tokyo, Japan; $20 \times 73$ mm, 48 g). 2015 to present. Photo $\odot$ DP Costa. c ARCGEO-13T archival data logger with temperature, depth sensors and geo-location via light levels (Lotek Wireless, St. John's, Newfoundland, Canada; $13 \times 57 \mathrm{~mm}, 12 \mathrm{~g}$ ). Early 2000s to present. Photo @ DP Costa. d Three generations of Argos-compatible satellite data transmitters commonly used as ETDs on pinnipeds made by Wildlife Computers Inc. (Redmond, WA, USA). SDR-T16 devices (top device in picture) were available through the late 1990s, measured up to $135 \times 45 \times 37 \mathrm{~mm}$ and had a mass of up to $330 \mathrm{~g}$ (depending on battery configurations). SPOT devices (middle) were introduced in the early 2000s. They measure up to $90 \times 55 \times 30 \mathrm{~mm}$ and have a mass up to $120 \mathrm{~g}$. A different configuration for a SPOT device introduced in the mid-2000s is shown at the bottom of the image above. This form factor with smaller batteries measures $85 \times 12 \times 12 \mathrm{~mm}$ and has a mass of about $23 \mathrm{~g}$. Antenna design has also changed through these years, leading to smaller and thinner yet longer lasting antennae. Photo $\odot$ M Horning

advent of integrated solid-state electronic circuitry in the early 1980s led to progressive miniaturization and to the evolution of sophisticated devices with multiple sensors and on-board signal processing (e.g., [39, 47]. Modern electronic ETDs come in many shapes, sizes, densities and masses (Fig. 2). Some of the smallest devices measure less than $10 \mathrm{~mm}$ in diameter and $30 \mathrm{~mm}$ in length, and have a mass in air under $30 \mathrm{~g}$, about 50 times less than the original Kooyman TDR.

Early devices functioned as archival data loggers that required recapturing animals to recover devices and gain access to recorded data. Recaptures were often facilitated through the use of VHF radio-beacons to monitor animal movement. In subsequent years, data telemetry systems have made it possible to remotely recover the data, though battery power and bandwidth limit the quantity of data that can be obtained (e.g., higher sampling rates, higher-resolution data, or data from additional sensors) unless the instrument is recovered. The Argos satellite location system ${ }^{1}$ was initially developed for global positioning of mobile transmitter platforms, but in later years was enhanced with the ability to receive limited amounts of data encoded in transmission bursts [107]. GPS-enabled animal-borne receivers greatly improved on the limited positional accuracy of the Argos system, but require device recovery, or a combination with Argos or mobile telephony (GSM) transmitters for data access $[22,75]$.

In the 1960 s and 1970s, the comparably large ETDs were often attached through removable full-body harnesses (see Fig. 1a, [37], or sometimes in combination with hog-rings to anchor small harnesses to the skin $[58,61]$. In a variation, anklets (ankle harnesses) were used on large pinnipeds such as elephant and Weddell seals (Mirounga spp., Leptonychotes weddellii) [18, 68].

\footnotetext{
${ }^{1}$ http://www.argos-system.org/ (retrieved 5/5/2019).
} 
The introduction of fast-curing adhesives (epoxies, urethanes, cyanoacrylates) allowed for the quick attachment of ETDs to the pelage of pinnipeds [29], Figs. 1b, d, 3) and represented a significant refinement by eliminating the need for subdermal anchors or harnesses, thus substantially reducing-though likely never completely eliminating-hydrodynamic drag [43, 111]. Electrical casting and embedding resins-sometimes in the form of syntactic resin matrices (syntactic foam)-enabled the elimination of large, heavy pressure housings, supporting significant reduction in device sizes. Miniaturization was further enabled by improved electronics and battery designs, resulting in some contemporary devices that are small enough to attach in the manner of interdigital ID tags (Fig. 1c, [6, 64]).

The use of adhesives to attach ETDs to the pelage of pinnipeds-while a refinement-limits the retention of the ETD to the period prior to the annual molt [31]. Other limiting factors to device longevity include battery capacity and size constraints. Larger devices with greater battery capacity increase hydrodynamic drag and thus locomotor cost and energy expenditure [72, 98], in addition to increasing the risk of entanglement, and visibility. Accessibility of animals for captures and ETD attachment also remains spatially and temporally constrained. Frequently, females and their offspring are captured in breeding areas during the reproductive season as they are the most accessible animals [37]. Safe captures, manipulations and ETD attachments involve physical restraint and often chemical sedation (Figs. 3b, 4, 5), and can remain challenging, especially if the possible bias associated with easy access in breeding areas during the reproductive season is to be avoided.

Despite these limitations, ETDs have enabled a wealth of observation-driven discoveries as well as manipulative experimental designs. In the early days, these were influenced by the need to recover archival tags. ETDs used in the classic isolated ice hole experiments on Weddell seals in Antarctica led to the first empirical determination of the aerobic dive limit and associated cardio-physiological adaptations [19, 60, 62]. In a less constrained setting using translocation experiments with high recovery probability, ETDs led to groundbreaking insights into the management of oxygen stores and fat stores of northern elephant seals (Mirounga angustirostris) [3, 5, 83, 84, 93, 120]. In a few instances, researchers have utilized the intrinsic drag of ETDs or additional devices as an experimental manipulation of the cost of locomotion [15, 72, 73] and more recently active acoustic ETDs have been proposed to more specifically and accurately manipulate the soundscape experienced by experimental animals [33]. Modern ETDs offer the opportunity to sample, record and

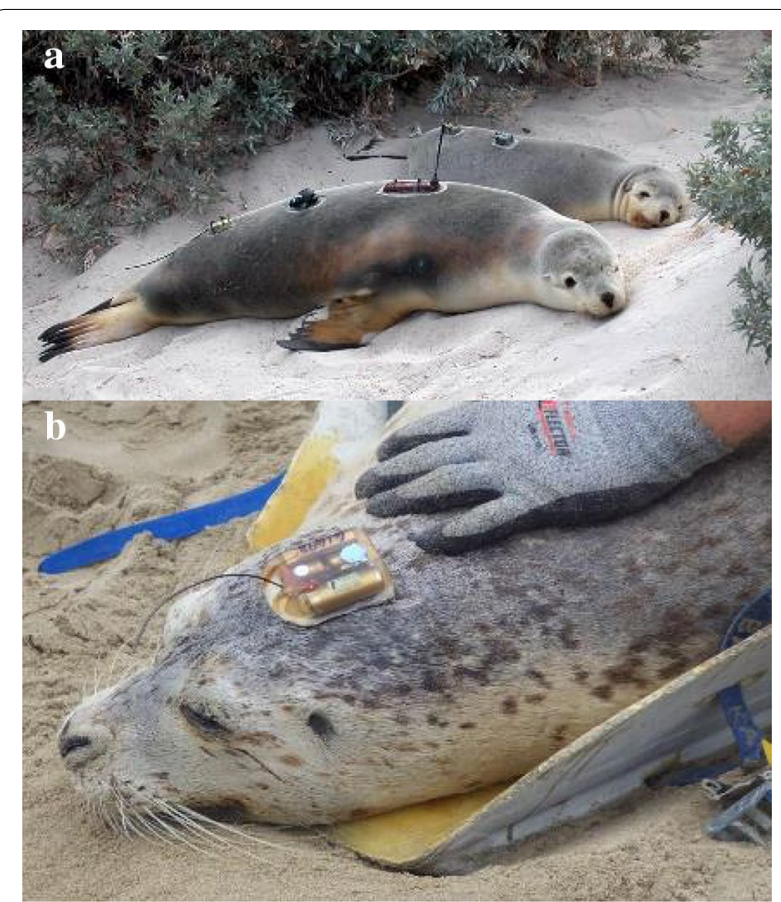

Fig. 3 Examples of optimal EDT configuration and attachments. a Australian sea lion adult female and 6-month-old pup at Kangaroo Island, South Australia, part of a research project investigating the ontogeny of diving and movement behavior and physiology [32]. The adult female is instrumented with (from head to tail) an Argos satellite transmitter (Telonics Inc., Mesa, AZ, USA), a Mk-6 depth and swim velocity data recorder (Wildlife Computers, Redmond, WA), and a VHF beacon (Lotek/ Sirtrack, St. John's, Canada). The pup is carrying a Mk-5 depth data recorder (Wild life Computers) and a VHF beacon (Lotek/Sirtrack). 6-month-old pups were not instrumented with Argos transmitters because earlier observations indicated that they did not leave the colony until they were older, making the additional instrument unnecessary (Recommendations \# 1,3, and 4). The instruments were attached to the animals using a 2-part quick-setting epoxy, with a layer of neoprene and mesh between the tag and pelage to allow for easy removal during recapture (Recommendation \# 9). Tags were attached in line along the dorsal surface to minimize disruption of laminar flow around the animal (Recommendation \# 8). Photo @ DP Costa, 2002, South Australian Department for Environment and Heritage permit \#G24475-2. b Attachment of a SPOT Argos transmitter (Wildlife Computers, $72 \times 54 \times 24 \mathrm{~mm}, 119 \mathrm{~g}$ ) to the head of an adult Pacific harbor seal in Oregon. The base of the tag was built up into a convex shape to conform to the curvature of the skull, and is then directly glued to the pelage surface with Loctite ${ }^{\mathrm{TM}}$ Type 422 ethyl-cyanoacrylate adhesive (Henkel Corp., Düsseldorf, Germany). No mesh is used to minimize the contact area to the tag footprint (Recommendation \#9 and 10). This adhesive sets within 10-30 s, and may generate some heat in the process. An alternative that produces less reaction heat for work in warmer climate can be found in Loctite ${ }^{\mathrm{TM}}$ Type 4861 ethyl/butyl cyanoacrylate that cures within 60s without generating much heat in the process. Type 4861 remains flexible on curing. However, achieving proper curing can be challenging, and may be facilitated through the use of accelerants (water or acetone mist). This deployment was part of an investigation into the spatial behavior of harbor seals, their use of marine reserves, and environmental drivers of their movement [110]. The lightly sedated animal is being immobilized on a V-shaped restraint board during the attachment (Recommendation \# 6). Photo $\odot$ SM Steingass, 2015, NMFS \#16691 


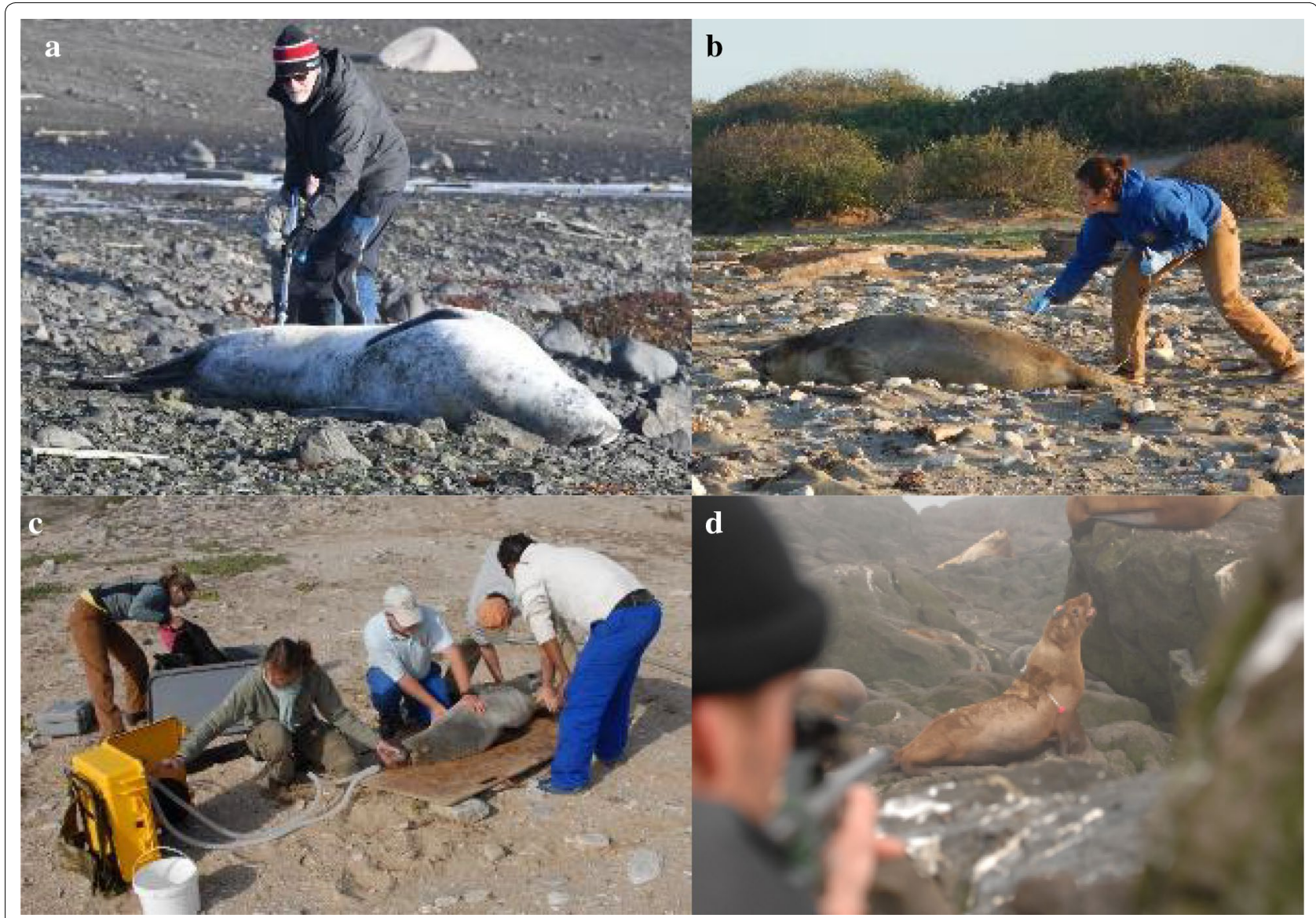

Fig. 4 Techniques for chemical immobilization and monitoring animals for ETD attachment procedures (Recommendations \#5 and 6). a Intramuscular injection of butorphanol and midazolam [96] in a leopard seal at Cape Shirreff using a pole syringe. Photo @ DP Costa, 2018, NMFS \#19439. b Manual intramuscular injection of tiletamine and zolazepam into a juvenile northern elephant seal at Año Nuevo State Park. Photo @ PJ Ponganis, 2019, NMFS \#19108. c This photo from the 1990s illustrates field isoflurane anesthesia of a South African fur seal on the northwest cape of South Africa using a portable inhalant gas anesthesia machine [34]. Note that contemporary standards require wearing gloves when handling an animal-unprotected contact does not meet best practice standards. Photo @ DP Costa, 2007. $\mathbf{d}$ Delivery of chemical immobilization using a $\mathrm{CO}_{2}$-propelled dart injector [46], for initial capture and recovery of a head-mounted archival GPS and dive depth tag. Note the syringe dart with pink stabilizer in the shoulder region of this Steller sea lion [116]. Photo @ RD [4], under permit by Rosprirodnadzor (Federal Supervisory Natural Resources Management Service of the Ministry of Natural Resources and Environment of the Russian Federation)

transmit many behavioral, physiological and environmental variables and parameters, including dive depth, swim speed, acceleration and orientation, fine-scale movement, flipper stroking, heart rate and venous oxygen partial pressure [76, 113, 123]. ETDs can provide information on body temperature, heat exchange with surrounding medium, prey capture attempts and ingestion events, and proximity to conspecifics [24, 49, 51, 54, 65, 70, 87, 90, 124]. More recently, environmental data collected from animal-borne tags have supplemented data collected from other platforms, including vessel-based sampling, moorings, and various types of passive and active autonomous samplers [11, 12]. In particular at latitudes higher than $60^{\circ} \mathrm{S}$, more environmental data have been collected by biological platforms (primarily southern elephant seals-Mirounga leonina) than by technical platforms [114].

Yet, despite continued improvements, manipulation of animals and the attachment of ETDs affect both host animals and nearby individuals, at various magnitudes and differing temporal and spatial scales [72, 73, 89, 98, 125]. This underlines the need to improve measures to assess, mitigate and reduce such effects. The well-known Guide for the Care and Use of Laboratory Animals provides few recommendations specific to research on wildlife [28, 91, 119]. In the United States, in the absence of ethical guidance on principles of humane animal research that is applicable to research involving wildlife, the National Science Foundation has requested professional societies to develop taxon-specific guidelines [105]. However, 


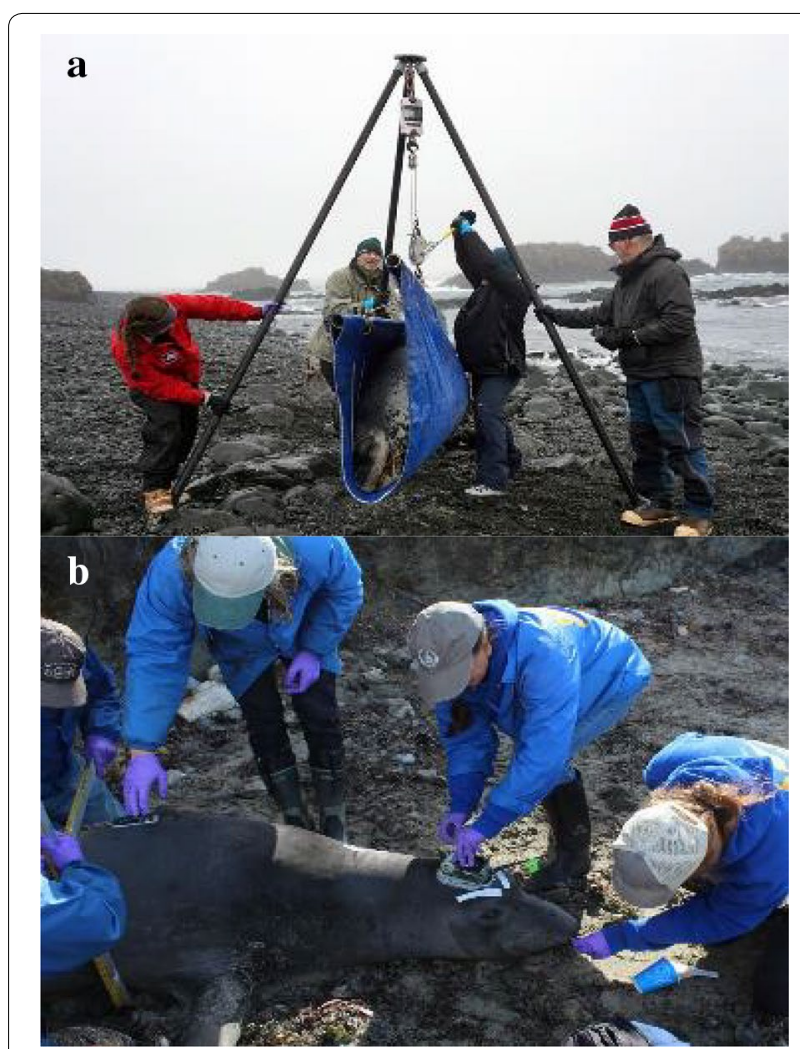

Fig. 5 Examples of field procedures on pinnipeds for ETD projects. Having enough experienced hands on a field team helps to ensure an efficient procedure and minimizes handling time (Recommendations \# 5 and 14); collection of ancillary data including morphometrics and tissue samples can enhance the value of ETD data (Recommendation \#3). a Weighing a leopard seal at Cape Shirreff during sedation for attachment of a Wild life Computers SPLASH10 Argos transmitter and TDR. This project combined physiological and behavioral sampling trying to match diving and movement behavior to blood volume, muscle myoglobin, and muscle fiber types. Photo @ DP Costa, 2018, NWFS \#19439. b An adult female northern elephant seal sedated for instrument attachment at Año Nuevo Reserve. The animal's breathing is being monitored while morphometric measurements are taken and nasal swabs are collected. One crew member is attaching a CTD-SRDL (SMRU Instrumentation) to the head of the animal with Loctite Quickset ${ }^{\mathrm{TM}}$ epoxy, with 5-mm neoprene and mesh between the tag and pelage to allow for EDT removal when the animal returns to shore. The animal's supraorbital whiskers are taped down to prevent them from sticking to the epoxy (Recommendations \# 9 and 10). A second crew member is attaching a VHF beacon (Advanced Telemetry Systems Inc., Isanti, MN, USA) to the back of the animal. The VHF transmitter is wrapped in splicing tape (3-M Temflex ${ }^{\mathrm{TM}}$ type 2155) and attached to heavy delta nylon weave $1 / 4$ " mesh with nylon cable ties. This deployment is part of ongoing research into the relationships between foraging behavior and body condition of northern elephant seals under varying climate conditions $[2,30,97]$. Photo $\odot$ RR Holser, 2017, NMFS \#19108

guidelines by the American Society of Mammalogists [104] provide only the vague recommendation that ETDs should not exceed $5-10 \%$ of individual body mass. The international Society for Marine Mammalogy provides some generic recommendations that apply to the use of ETDs in marine mammals, and encourages the conduct and publication of studies of short-term and long-term effects of tags [35]. It also provides a number of broad recommendations with respect to general study design and justification, subject selection, captures, restraint and sedation, animal procedures, including marking and tagging. A recent publication has compiled best practice recommendations for tagging cetaceans [4]. Here, we provide comprehensive and specific Best Practice ${ }^{2}$ recommendations for the use of ETDs on pinnipeds, which we have synthesized from our collective experience. These recommendations should be considered by researchers preparing projects and by regulatory bodies authorizing projects. Our recommendations are not societal guidelines and supplement rather than supersede many previously published recommendations on animal research, capture, handling, sampling, captivity, and telemetry. They are specifically tailored towards the current use of contemporary telemetry devices on pinnipeds compared to most extant societal guidelines. These initial recommendations may be refined or adjusted through new studies, within the guiding principles of the Three Rs: Reduction, Refinement, and Replacement [99]. While we developed these recommendations specifically for pinnipeds, some may be applicable to other groups of aquatic animals, such as other marine mammals or aquatic birds.

\section{Methods}

This compilation of recommendations follows an earlier effort on implanted telemetry devices [52]. A number of researchers that have published studies using ETDs or are actively using ETDs. ${ }^{3}$ were contacted by the lead author with an invitation to participate. The intent was to include expertise from historic and contemporary studies, from both established and early career researchers with backgrounds in behavior, physiology, ecology, and veterinary medicine. Twenty-four of 30 contacted researchers participated, covering 29 pinniped species ${ }^{4}$ in all oceanic and coastal regions of the world, as well as many estuaries,

\footnotetext{
${ }^{2}$ Best Practice defines procedures that are accepted in the field as superior to alternatives by producing best results, most positive outcomes, or minimal negative consequences; and are based on evidence synthesized from prior efforts.

${ }^{3}$ Determined via presentations at recent conferences, including the 6th International Biologging Symposium held in Konstanz, Germany, in September of 2017.

${ }^{4}$ Hawaiian monk seal (Monachus schauinslandii), harbor seals including Pacific (Phoca vitulina richardii), North Atlantic (P. v. concolor) and European ( $P . v$ vitulina), southern and northern elephant seal, Weddell seal, Ross seal (Ommatophoca rossii), crabeater seal (Lobodon carcinophaga), leopard seal (Hydrurga leptonyx), ribbon seal (Histriophoca fasciata), spotted seal (Phoca largha), bearded seal (Erignathus barbatus), ringed seal (Pusa hispida), gray seal (Halichoerus grypus), California sea lion
} 
lagoons, and lakes. The authors' collective expertise is based on approximately 6400 deployments over 445 person-years. Device types used include mechanical, optomechanical and electronic archival data loggers, and data transmitters using UHF, GSM and Argos data links. Location tracking devices include VHF, GPS and Argos, geolocation by light, as well as active acoustic and deadreckoning-based location tracking while submerged. Device sensors used include ambient pressure, internal-, external-, and transmitted temperature, heat transfer (heat flux), movement speed (swim speed), triaxial accelerometer, magnetometer and gyrometer, electrocardiography, as well as a variety of environmental sensors. Animal-borne video and acoustic recording devices are a relatively recent addition to the repertoire. Experimental designs applied by members of the group include telemetric behavioral and physiological observations, as well as experimental manipulations including isolated ice hole work (see [61], translocations, cost of locomotion (drag) manipulations, and animal-borne active ensonification. Projects include work on wild animals and those in captivity (both permanent collection residents, and those held temporarily). Attachment techniques applied have changed considerably over the decades and include hogrings in the early years, anklets, harnesses, bolts (e.g., through interdigital skin on flippers), and many types of adhesives. Programmable or remote-controlled release mechanisms have also been used. Capture and restraint methods include head-bagging, netting in water and on land or ice with hoop nets, throw nets, purse nets, and tangle nets, underwater noosing, and chemical immobilization by dart or by direct injection. Restraint and sedation techniques include the use of restraint boards and injectable and inhalant anesthetic agents.

To assemble a list of contemporarily relevant recommendations that describe the current state-of-the-art, participants were asked to each provide their fifteen most important recommendations. All responses were compiled, identical or substantially overlapping recommendations were combined, and similar recommendations were grouped into related classes. This led to an initial list of 100 recommendations with a substantial level of redundancy (Additional file 1: Table S1).

\section{Footnote 4 (continued)}

(Zalophus californianus), Steller sea lion (Eumetopias jubatus), Australian sea lion (Neophoca cinerea), New Zealand sea lion (Phocarctos hookeri), Galápagos sea lion (Zalophus wollebaeki), Antarctic fur seal (Arctocephalus gazella), Guadalupe fur seal (Arctocephalus townsendi), Galápagos fur seal (Arctocephalus galápagoensis), New Zealand fur seal (Arctocephalus forsteri), northern fur seal (Callorhinus ursinus), South American sea lion (Otaria byronia), South American fur seal (Arctocephalus australis), South African fur seal (Arctocephalus pusillus), and walrus (Odobenus rosmarus).
Participants were then asked to indicate whether any of these 100 recommendations should be removed because: (a) it is already obligate or required by legislation or permits (6 eliminated), (b) is already covered by an extant best practice compilation (4 eliminated), (c) is not current state-of-the-art, but is instead a desired future development (9 eliminated), (d) deemed too prescriptive (1 eliminated), (e) insufficiently broadly important for a best practice recommendation (2 eliminated), or (f) the recommendation should be combined with one of the others listed (3 combined). Any single suggestion of removal resulted in an initial elimination or combination, and participants could object to any of these eliminations, but none were contested.

The remaining 68 recommendations were grouped in 19 classes, and participants were asked to rank their top 15 classes. Rankings were compiled and averaged, and the 6 lowest ranked put to vote for either retention (2) or combination with others (4) or elimination (none). This resulted in a final 15 classes of closely related recommendations.

These classes are presented here as the 15 most important recommendations derived by the 24 authors.

\section{Best practice recommendations}

Pinniped researchers have primarily relied on their own experience tagging animals, knowledge gained from colleagues, and information from select published studies to justify and improve the use of external telemetry devices (ETDs) and to design experiments and devices. Here, we propose 15 specific recommendations to guide investigators and regulators in preparing and reviewing applications of ETDs in pinnipeds based on our collective experience over the past decades. We specifically exclude fully or partially implanted devices, where the entire device is implanted or where a portion of a device, other than the attachment mechanism, breaks the integument (see [52] for best practice recommendations on implanted devices). The recommendations are grouped into the following seven broad categories: justification, capture, tag design, tag attachment, effects assessments, preparations, and reporting.

\section{A. Justification of the use of ETDs, selection of appropriate experimental design and choice of subjects \\ 1. The use of ETDs should be justified for specific exper- imental designs in view of risks for and effects on ani- mals, importance of data, and potential alternatives.}

Bateson's cube [9] and its more recent application in a conservation framework [82] considers the ethical risk of and support for research based on three parameters: the quality and importance of the research, the certainty of benefit to the species under study (where any protected 
status of the species of interest should be considered), and the animal suffering caused by a study. Thus, quality and benefit of the research are required to justify any animal suffering. For any particular study, animal suffering can also be reduced by consideration of the Three Rs: Reduction, Refinement, Replacement [99]. Generally, Reduction is interpreted as the use of fewer animals. Collaborations and the possibility of combining multiple projects or experiments can reduce the number of animals used, which may also reduce the number of projects at one site and instances of group disturbances. Sample size may also be reduced by collecting more or higher-resolution data per subject. Refinements are improvements in experimental procedures that result in fewer negative effects on animals or improved animal welfare. For example, smaller tags or fewer tags per individual have the potential to reduce or eliminate drag-related energetic costs associated with ETDs. Replacement avoids the use of animals altogether, finding alternative ways to obtain the desired information. For example, this could be implemented through the use of existing high resolution, high density data sets that may lead to enhanced opportunities to use computer models to simulate animal responses to situations or the environment. Other alternatives to ETD use might include: direct or remote video observations of individual animals using temporary, permanent, or natural markings; genetic studies; acoustic tracking; as well as other approaches. However, replacement may not necessarily be a viable option. Valid justifications for ETD studies include: the predicted data recovery probability with sufficient statistical power, resolution, or sensitivity is too low for any alternative; the alternatives are likely to result in greater impacts on individuals or greater disturbances to large groups; or simply that important data cannot be collected by any other means. In addition to these ethical considerations that may influence experimental design, ETD studies are further affected by the need to consider mode and likelihood of data recovery. Tag failure and non-recovery (e.g., loss of transmitting tags or failure to recapture animals instrumented with archival tags) will affect the balance between possible negative effects on animals versus benefits of the research.

\section{Conduct a sample size estimation during project planning.}

The required number of ETD deployments should be estimated during the project design phase via an appropriate a priori power analysis, when possible for nonexploratory hypothesis testing and where analyses are specified at the design stage (see [101]. However, this is only possible where data on variance are available or can be projected or modeled. Where such information is not available, exploratory or proof of concept projects on a few animals might be warranted. An alternative estimation based on a review of published telemetry studies by study type in relation to their sample sizes has been proposed [101]. Studies using ETDs should also consider realistic deployment durations and available data on activity (proportion of time spent in relevant activity such as diving or migrating). An appropriate sample size estimation should account for possible failure at several key places: tag electronics and operational software, tag attachment, animal recapture and/or data recovery-any of these may increase with planned deployment duration. For long deployments (e.g., more than a few months), the likelihood of natural mortalities must be considered. Higher-resolution devices, higher sampling rates, or longer-duration deployments may enable smaller sample sizes, under some circumstances. Project planning should also include data recovery strategies that are based on realistic projections, but potential effects of these strategies (e.g., recapture) also need to be considered and where possible accounted for. For recaptures, knowledge of seasonal patterns in site fidelity may be important. Common data recovery approaches could be supplemented through novel, emerging technologies (e.g., shore-based, automated Argos message relay systems (e.g., [55], or the installation of mobile telephony repeaters).

\section{Optimize ETD selection, programming, and collec- tion of ancillary data.}

Critically evaluate available technology to select the ETD to best meet project objectives. Sensor selections, ranges, sensitivity and resolution should be considered, as well as battery life, storage capacity, and available attachment configurations based on device design. Device and sensor selections as well as programming need to be appropriate for study species and expected behavior [16]. Optimal device programming typically requires knowledge of duration and magnitude of the effects to be monitored. Short-duration events and those of small magnitude require higher sampling rates and greater resolution to detect [14]. Ideally, instruments that minimize hydrodynamic effects on animals are preferable to those that are bulkier and less streamlined. Combining functions into fewer instruments is preferable as long as this configuration does not unnecessarily increase instrument size and $\mathrm{drag}$, as is maximizing the information collected from all available sensors. We specifically recommend maximizing the collection of all possible ancillary data if this can be done with no or little additional effect to the animal. This approach can significantly enhance the value and interpretability of the data and power of the study, can support the Reduction component of the Three Rs, and can also enhance future opportunities to Replace (via 
re-use of data for other studies). Recommended ancillary data for ETD studies includes collection of morphometric measurements and tissue samples to allow estimation of body condition (see [108], baseline health assessments (e.g., [38] and age determination [100] at the time of capture and ETD deployment, but could also include application of long-term or permanent, natural or applied markings (see [94, 118], behavioral observations, resights, and collection of environmental data.

\section{Select appropriate research subjects.}

The most appropriate experimental group composition for the question should be determined in view of possible tag and procedure impacts. Criteria to consider include sex, age, and size, as well as body condition or reproductive state. Following this a priori determination of group composition, experimental designs should consider establishing in situ animal selection criteria. When the selection is not critical to the sampling design (i.e., differences in health status, size, age or other criteria are not the focus of the study), animals with lower risk of complications or those likely to have a lower population-level impact, could be selected (e.g., larger or older animals, males). The inclusion or exclusion of animals as a function of their health status (e.g., body condition, injuries) is an important ethical consideration and can also increase data return probability and enhance data quality. However, use of such criteria may introduce biases in estimates (e.g., behavior or survival) that may or may not be correctable if the interest lies in understanding the entire population (see [7]. It is important to also consider and minimize potential subject selection biases based on location, time of year, animal capture procedures, and animal behavior. Timing of captures in relation to the pelage molt will affect ETD deployment duration and data recovery probability. We further recommend to derive and apply a post hoc study inclusion criterion: unless otherwise proven, it should be assumed that animal manipulations and ETD attachment will affect a subject's behavior, at least initially (see also Recommendation \#11). The study inclusion criterion should be based on the empirical determination of the time after which behavior and data are no longer affected by the treatment.

\section{B. Capture and restraint}

5. Minimize manipulations, duration of restraint and captivity.

Initiating an acute stress response is unavoidable when capturing and handling wild animals [42], however the application of best practices can reduce the likelihood of stress progressing to highly negative outcomes such as capture myopathy (e.g., [102, 109]. While the use of chemical restraints to mitigate capture and handling stress is widely used as standard practice in pinnipeds (see Figs. 3b, 4, 5), there is a large degree of individual variation in behavioral and physiological response to capture stress even with the use of sedatives and tranquilizers [41]. Manipulations of research subjects should be kept to a minimum and the duration of restraint, transport and temporary captivity should be carefully considered within the framework of what is needed to achieve study goals while minimizing the negative impacts on individuals [17]. Multiple handling events should be well justified and their effects accounted for [80].

Researchers should only use appropriate handling and sedation methods (recommendations \#6 and \#7) with trained personnel (recommendation \#14) to make the manipulations as efficient as possible and minimize negative effects. The use of temporary captivity should be carefully considered especially due to the extended stress that it may impose on study subjects. Every effort should be made to release all individuals at the same location at which they were captured. A special case of this may be where individuals equipped with ETDs are translocated to investigate aspects of energy expenditure and dive behavior over a known distance (e.g., [3, 36, 48, 72, 73, 83, $93,120]$. While translocation is already a common tool for ETD studies in pinnipeds, every effort to minimize stress should be taken during handling and transport of subjects and the method should be well justified within the study framework [25].

In addition to minimizing the effects of capture and restraint on target animals, researchers should also consider the potential effects of research operations on nontarget animals and/or other species within the study area. When working in a breeding area, researchers must consider whether and to what extent the presence of a capture team may cause other individuals to change their behavior and flee the capture location. For instance, researchers may need to weigh the impact of capturing two animals at a time against disturbing an entire colony twice. The impact of captures on nearby individuals will vary by species. In addition, ETD studies often target pinnipeds during the reproductive season. When capturing lactating females with young, dependent pups (classification of young is species dependent), pups should be maintained nearby either within a natural crèche or within a pup box, bag, or net. Upon release of lactating females, pups should be released simultaneously nearby or adjacent to the female and researchers should make every effort to reunite mothers and pups where possible to minimize the chance of abandonment. 


\section{Use appropriate capture and restraint methods.}

The method used to capture and restrain an animal should minimize risk, stress, and pain to the subject while also ensuring the safety of personnel. Pinniped species vary widely in their habitat choice, response to human presence [27], physiological reactions to both physical and chemical restraint, and the danger that they pose to researchers [88]. Consequently, specific immobilization methods vary between species and situations; careful consideration is needed to develop a capture plan, and research teams should always include personnel experienced with the study species (see also Recommendation \#14).

The Society for Marine Mammalogy provides specific guidelines for three aspects of animal capture: (1) the design of physical restraint equipment, (2) when some form of anesthesia should be used, and (3) drug and technique choices [35]. These guidelines provide a useful framework when designing a plan for handling any pinniped species for ETD attachment. Three chapters on pinniped capture and immobilization in Zoo Animal and Wildlife Immobilization and Anesthesia [121] provide a good starting point for developing new capture plans, although the focus is on work with captive animals and it is still critical that investigators work with researchers experienced with the species and system in question. Researchers should frequently search for new literature on novel techniques and revised drug recommendations to refine their established protocols (e.g., $[1,10,13,56$, $69,79,85,86,92,96]$.

Whenever possible, adding ETD attachment to already scheduled anesthesia procedures is worthwhile. While sedation and anesthesia can reduce stress to the animal and danger to personnel [20], they do pose risks to the animal $[46,95]$. Species-specific monitoring and emergency protocols should be established prior to handling any animals and should outline vital signs (respiration rate, heart rate, capillary refill, palpebral reflex, etc.) to be monitored throughout handling. In the event that an animal responds poorly to handling, contingency measures outlined in the emergency protocol should be followed under the guidance of the most experienced person present (see also recommendation \#14).

\section{Recognize and manage potential thermoregulatory stress and protect eyes during capture and restraint.}

Being on land exposes pinnipeds to unique thermoregulatory demands that are not similarly experienced by fully aquatic marine mammals, and pinnipeds have been shown to elevate body temperature when challenged with warmer external temperatures, suggesting they are moving beyond their thermoregulatory limits $[67,115,122]$. Small or very young animals and those in poor body condition may experience hypothermia in cold climates, especially while sedated. Researchers should understand the thermoregulatory mechanisms of the species and/or taxon [57] and age class [26] with which they are working. Since normal behavioral mechanisms for thermoregulation are restricted during capture, restraint and sedation, animal temperature should be closely monitored during handling, if possible (e.g., via visual behavioral monitoring for stress, movement, panting, salivation, or via infrared thermography, or rectal or tracheal thermometry). Signs of thermoregulatory stress in mammals are described by Silanikove [106], and additional thermoregulatory considerations for wildlife work can be found in Sikes [104]. Prevention of thermoregulatory stress can be initiated during project design by considering or managing conditions (ambient temperature, wind and availability of windbreak or shade) at the procedure location. In cases where the study animal appears to become overheated, researchers should cool tissues of strong thermoregulatory value, including fore and hind flippers, with water [112].

Animals may experience eye damage during prolonged exposure to solar radiation; this risk is enhanced by a decreased ability to blink during sedation or anesthesia. Eyes should be covered with a UV-resistant and nonabrasive material during restraint to both protect the eyes and to reduce stimulus to the captured animal. In addition, a gel-based solution of artificial tears can be applied to protect the eyes of the animal. Under light sedation, animals may retain some visual acuity, so covering the eyes will not only aid in protection, but also will help to reduce handling stress for most species.

\section{Tag design}

\section{Optimize and validate safe tag designs.}

ETDs can have measurable effects on their host animals: they may increase the cost of locomotion or thermoregulation, alter foraging, social and reproductive behavior, change the detectability of hosts by predators or prey, or increase the risk of entanglement [42, 89, 117]. In extreme cases, negative effects of ETDs could lead to injury or even death of the host. Designs should, therefore, minimize these risks by optimizing: device size in terms of footprint, shape and drag (including aspect ratio and frontal area), mass and density (weight in air, and buoyancy), the shape and length of external device components (length and size of external sensors and cables, and of antennae) and the drag these cause, and attachment location (in terms of drag and interference with normal behaviors)-where possible. The color and sensory appearance of the tag, both to the host animals and others, particularly predators/prey, also warrant consideration (see recommendation \#12). 
Another critical device design and selection aspect is the pressure rating. Electronic tags, in particular those containing lithium batteries, can critically fail when pressurized beyond design depth. This can lead to burns and other injuries. For implanted telemetry devices, where such failures are likely fatal, a margin of safety aiming for $3 \times$ the average reported maximum depths (for target animals) was recently proposed [52]. A similar safety margin would also be appropriate for external devices. Users should also consider the potential for tag ingestion by a predator, which might necessitate considering predator dive depth in choosing tag depth rating.

Finally, the environmental impact of discarded, nonrecovered tags should be considered. The occurrence of derelict tags should be minimized, and for non-recovery projects, minimizing the use of toxic or reactive materials (heavy metals, certain battery electrolytes) should be favored.

\section{Tag attachment \\ 9. Optimize tag attachments.}

The attachment method and instrument location will be influenced by the size of the device and project goals. With recent miniaturization, direct attachment methods have become increasingly effective. Different attachment locations are subject to different constraints. Headmounting generally improves transmission frequency and quality but restricts device size and likely increases the hydrodynamic load, and may have other unmeasured effects on behavior. Back-mounting often allows for attachment of larger devices, but exposure constraints limit uplinks. Accelerometers and other sensors may detect different activities or behaviors depending on attachment location, and device-induced hydrodynamic drag may also differ. Tag removal may be more challenging from some attachment areas than others (e.g., it may be more difficult to remove tags attached to the head). Additionally, the optimal choice for attachment method and location will be influenced by environmental conditions, animal habits and haul-out substrate (e.g., rocky shores, sandy beaches, ice, or mostly pelagic habits).

Where possible, attachment locations should be chosen to minimize effects on animals, and methods should be appropriate for planned deployment durations while minimizing handling (i.e., a permanent attachment may not be appropriate for a tag with a short battery life). Devices should not be placed directly over highly flexible areas, or on joints. The footprint should be minimized while also minimizing likelihood of tag loss. Generally, there is no need for a footprint larger than the tag. Harnesses or other high-drag attachments with high entanglement likelihood should only be used for very short periods and under highly controlled conditions such as captive or trained animal projects, or possibly translocation experiments, and only when risks can be mitigated (e.g., in a controlled setting or via the use of corrodible links in harnesses). Overall, the ease and safety of device removal should be considered. To maximize the chances for recovering data from ETDs that might be shed and found by humans or retrieved by hunters from species taken for subsistence, identifying information should be displayed on devices; this is also important to subsistence users who may wish to know the history of a harvested animal that has been tagged.

\section{Select suitable attachment materials and appro- priately test and apply.}

Modern adhesives are probably the most common form of ETD attachment to the pelage of pinnipeds [31], see Figs. $1 b, d, 3$. This is highly effective and generally very safe, but improper application can result in skin irritation, skin abrasions and punctures, burns or other skin damage, and secondary infections (see [31]). Exothermic setting adhesives (two-component epoxies and accelerated cyanoacrylates) generate heat (often subject to environmental conditions) that can result in severe, third-degree burns. This can be avoided by reducing the amount and depth of adhesive applied, sequential application of multiple thin layers rather than a single thick layer, the reduction or avoidance of accelerants, minimizing direct sun exposure, or the application of cooling packs or pre-cooled tags. However, there is a trade-off between reducing generated heat and impeding adhesive curing, and in extremely cold climates heat packs may be required to maintain temperatures adequate for curing. Mechanical action and wear of attached tags can sometimes be mitigated by soft transitional or carrier material such as neoprene, but such layers may also trap heat during the setting reaction. Fur can also effectively serve as a transitional material if tags are glued to only the outermost layer of the pelage (Fig. 3b). Directly gluing to the skin should be avoided, if possible. For archival devices that require recovery and for multiple deployments (e.g., double translocation), consider easy removal and reattachment methods to avoid reapplying glue, such as gluing netting to the pelage and attaching ETDs with cable ties (see Fig. 1d). Overall, the thermal and chemical properties, processing time, attachment life, and ease of removal of adhesives should be carefully selected to minimize adverse effects, and reasons for product selections described in publications of methods, if possible. 


\section{E. Effects and impact assessments}

11. Plan, conduct and report on short-, medium- and long-term assessments.

The deployment of ETDs can cause behavioral changes, may affect welfare and even survival of the host animal, and could also influence the data collected. It is important to include effects assessments in study designs both in terms of basic principles of the scientific method, as well as principles for the ethical treatment of research animals. Even for modern miniaturized ETDs attached in comparably non-invasive ways, impacts have been investigated, and effects reported in the form of increased drag, cost-of-transport, and thermoregulatory expenses [72, 74, 98, 117, 118, 125, 126]. When transmitting devices 'go off the air' (i.e., transmissions cease to be received), battery exhaustion, device or attachment failures are often assumed, but process- or device-related fatalities are rarely considered, and long-term effects rarely studied. Devices and procedures may also generate effects beyond the data collection period that may only become apparent through control studies or continued monitoring.

As a result, possible effects should be considered and assessed across three broad time periods:

(a) Short-term effects ranging from hours to days that are most likely related to capture and manipulations, and may inform a study inclusion criterion (see Recommendation \#4). Examples may include stress and anxiety through separation from conspecifics, and effects related to sedatives including disorientation, reduced appetence, mobility, or altered vigilance.

(b) Medium-term effects ranging from days to months are critical in determining possible influences on data. Until demonstrated otherwise, it should be assumed that tagged animals may exhibit increased cost of locomotion or altered performance, which may also affect their foraging ability and other behaviors. Some studies have found measurable energetic effects even for small devices [98], while other studies have found no such effects [81].

(c) Long-term effects ranging from months to years, possibly beyond the data collection period. Some effects may have low level accumulating impacts that may become more detectable when integrated over longer periods of time, or over multiple sequential deployments $[8,72,126]$. Suitable metrics for effect assessments should be carefully chosen, since effects may occur outside of the selected suite of primary experimental metrics. Short- and medium-term effects could be studied at the level of proximate mechanisms, and long-term effects could more readily be assessed via ultimate impacts on growth (including growth of dependent offspring), migration, and fitness (e.g., [103]. The selection of appropriate control groups is an important aspect of effects assessment that can also enable creative approaches. For example, assessments can be based on classic comparisons to un-instrumented, non-manipulated control animals, or alternatively on animals carrying different types of external or internal devices with previously quantified effects. Experimental animals serving as their own controls may also be an option, through second observation periods with altered device configurations, or simply through extended observation periods (e.g., [45]). Any recaptures or resights of tagged animals should include efforts to assess status and evidence of effects. Often, such studies may be enabled through common, concurrent population monitoring programs based on marked or tagged individuals. Alternative assessment approaches may include captive animal studies under controlled conditions, such as energetic studies on device-altered cost of locomotion (e.g., $[72,98])$ or cost of thermoregulation (e.g., [74]). Any evidence of effects should be addressed and incorporated into refinements.

It cannot be assumed that ETDs will have no impacts simply because no effects have been found in some other devices or on a different species, since effect magnitudes appear to be specific to device shape, mass, size, attachment method and location, as well as animal state and circumstances [17]. For example, animals may have a greater buffer to adjust to increased device drag when conditions are good, but have no or limited ability when conditions are poor or food is scarce. The likelihood of an effect for a species/device combination is, therefore, never certain, and studies should be conducted with caution. It is prudent to carry out and report control studies when possible (but note Recommendations \#1 and \#2) $[17,118]$.

\section{Validate ETDs for any new tag/species combination.}

Given the range of possible effects of ETDs and procedures on their hosts, and in view of evidence of specificity of effects $[89,125,126]$, it is important to assess effects for every new device/attachment-species combination, and to mitigate or minimize any detectable effects. For critically listed (i.e., endangered) species, the absence of negative effects should be validated, where possible, on a suitable surrogate species (i.e., similar or related, but not critically listed), or on stranded animals after rehabilitation (and see also Recommendation \#4).

\section{Consider active and passive device detectability.}

ETDs may alter the detectability of animals to conspecifics, predators or prey, in a variety of ways based on different senses. Tags and attachments may be more or less visible depending on size, shape and coloration. All electronic tags produce electromagnetic signatures through 
periodic sensor sampling, operational activities, transmissions, or by their metal mass (e.g., battery) moving through salt water. Tags may generate active and passive acoustic signatures that could be detected by predators or prey. Such emissions could also be perceived by host animals and alter behavior. Tags may also be echogenic, altering the detectability of their hosts by predators employing active echolocation. ETDs should be selected and attached in a manner that minimizes these effects.

\section{F. Training, testing and preparation} 14. Preparation and training.

The capture and handling of animals has inherent risks for both the animal and personnel involved. Guidelines provided by both the Society for Marine Mammalogy [35] and the American Society for Mammalogists [104] direct researchers to ensure that personnel working with animals in the field have appropriate training and experience to ensure the safety of those involved and the successful collection of data.

Pinniped captures can be particularly risky for both animals and researchers if team members are not adequately prepared. Generally acknowledged risks include physical injury, hyperthermia, excessive stress and capture myopathy, overdose of sedative drugs-some of which can lead to death in extreme cases, but also mother-pup separation or aggression by conspecifics, as well as zoonoses (diseases transmitted from animals to humans) and zooanthroponoses (diseases transmitted from humans to animals). Research teams should be of sufficient size and experience to capture, instrument, monitor, and safeguard the animals and to respond to emergencies if necessary. This should ideally include species- and location-specific experience. All team members should have clearly designated roles and responsibilities, and should be familiar with pertinent emergency response plans. Appropriate emergency drugs and equipment must always be present and personnel need to be familiarized with their use prior to animal handling.

Careful preparation and planning are essential for successful and safe work in the field and help to minimize unfruitful animal handling. All ETDs should be tested prior to attachment on animals. This includes testing that all sensors and transmitters are functioning correctly, that clocks are appropriately synchronized to allow for subsequent time drift correction, and that tags will not interfere with each other if multiple instruments are to be deployed on an individual. For custom-built housings and instruments, it is critical that devices are pressure tested beyond the maximum expected dive depth of the target species. Some ETDs may require pre- and/ or post-deployment calibration (i.e., swim speed sensors, fluorometers, etc.) to maximize the accuracy of the data collected.

In addition, when working with a new protocol or new crew, running through the steps of the capture and instrument attachment procedure ahead of time will help to increase efficiency and minimize confusion in the field. This process should be mirrored after field work has been completed. Taking the time to debrief after animal handling procedures is an essential step to refining protocols, enhancing the training of less experienced personnel, and increasing efficiency for future deployments.

\section{G. Reporting, analyses, data management 15. Reporting.}

In support of the application of the Three Rs, it is critically important that all findings are reported in readily accessible (e.g., Open Access) peer-reviewed literature. Once published, all metadata (preferably in standardized format), data and analysis code/scripts should be placed in a discoverable and accessible repository. Publications should specifically describe details that are integral to effects assessments, and thus to future refinements, and should minimally include these metrics: tag attachment method (e.g., glue type) and location, footprint size of tag/glue area, tag mass, density (or buoyancy) and frontal area. If a tag is of a novel or unique design, a photo is appropriate to illustrate shape, coloration, and visibility. It is also highly recommended to report observed data collection durations and data recovery rates, and if possible distinguish between end of record modes (battery exhaustion, attachment failure, predation/mortality, or unknown). Publications should include reports of problems encountered, effects observed, and should suggest improvements.

\section{Conclusions, caveats and future directions}

These 15 best practices represent what we feel are stateof-the-art recommendations for projects using ETDs to study pinniped ecology, behavior, physiology, and hydrography. We suggest following these recommendations in conjunction with any societal and institutional guidelines in designing, preparing and implementing projects. Any deviation should be convincingly argued to regulatory bodies, ethics review committees, journal editors and referees. At the same time, it will be critically important to avoid creating a situation where studies are constrained until the minimization of impacts has been demonstrated, as this cannot be accomplished without risking such effects. New techniques and approaches in particular cannot be developed and trialed without incurring such risks. We specifically call on regulators to avoid the 'over-regulation by specificity trap', whereby desirable and important studies are curtailed through 
progressive reduction in flexibility and ad hoc, in situ decision-making that are key to the effective implementation of best practices in wildlife research (see $[28,119]$.

The further development, evolution, and improvement of best practices should be pursued within the framework of the Three Rs [99]. While eliminated from our original, unvetted list of 100 recommendations as not currently state-of-the-art, the following aspects represent desired future directions in the field, and are presented here around 4 main themes.

(a) Technical developments: A desired future direction facilitated through stronger connections between tag developers and researchers is to pursue, test, and integrate new sensors, leading to increased capabilities, smaller tags, and longer life. Within these goals, the development of ETDs capable of collecting multi-year data would enable many additional experimental designs and projects [6]. This may require novel attachment techniques that may be facilitated through smaller devices. For these long-term deployments, future developments should seek to integrate energy harvesting mechanisms to increase the life of the tag, while minimizing the need for large, heavy batteries. Concomitant with this, the further development and wider availability of small, reliable remote release mechanisms would allow the elimination of a second handling period for device recapture and would likely increase data recovery probabilities.

(b) Validation of energetic proxies: A second future direction strives to pursue more species-specific validations of energetic proxies from tags. There have been a great number of studies in recent years that have attempted to link data from ETDs, such as accelerometry, activity partitioning, movement data or dive profiles, to robust models of energy usage over time. Using tag data that have not been properly calibrated to energy usage can be problematic and lead to spurious correlations and risks falling into the so-called 'time-trap' (merging measurements such that time is on both sides of an equation, as discussed in [40, 66], but may be difficult to assess for certain species.

(c) Expanding life history studies: Our third future direction expands studies on ontogeny, reproduction and survival. Tagging techniques and studies should be developed that facilitate understanding of ontogeny and link existing data to survival, recruitment, and ultimately to fitness. Data on diving behavior, movements, and migrations collected from ETDs on individuals should be linked with data on reproduction and survival of animals, especially beyond the tagging period. This would lead to powerful new experimental designs, with substantially increased scope of testable hypotheses and the ability to investigate questions previously labeled as 'empirically intractable' that will improve our understanding of population-level consequences of different behaviors and tagging regimes.

(d) Data accessibility and sharing: The fourth future direction is to pursue enhancements and improvements of data portals for sharing telemetry and ancillary data. A number of databases already exist, such as the Integrated Ocean Observing System (IOOS), ${ }^{5}$ Animal Tracking Network (ATN), ${ }^{6}$ Marine Mammals Exploring the Oceans Pole to Pole (MEOP-CTD Database), ${ }^{7}$ and MoveBank. ${ }^{8}$ This is a challenging effort that is already well underway, and we encourage researchers incorporating ETDs into pinniped studies to continue to push for accessibility developments and highly recommend their participation in these databases, even when not obligatory.

\section{Supplementary information}

Supplementary information accompanies this paper at https://doi. org/10.1186/s40317-019-0182-6.

Additional file 1. Initial list of 100 recommendations compiled by the authors before the elimination of redundant entries. Similar recommendations are grouped into related classes.

Abbreviations

ETD: external telemetry devices; TDR: time depth recorder; VHF: very high frequency; UHF: ultra high frequency; GPS: Global Positioning System; GSM: Global System for Mobile Communications.

\section{Acknowledgements}

Not applicable.

\section{Authors' contributions}

MHo conceived concept, compiled recommendations, wrote manuscript with $\mathrm{RRH}, \mathrm{CRS}, \mathrm{SMS}, \mathrm{CRM}, \mathrm{CLW}, \mathrm{SKH}, \mathrm{AGH}$. All authors submitted recommendations and voted on rankings, commented on and edited manuscript drafts. All authors read and approved the final manuscript.

Funding

Authors were supported as follows: MHo by the Alaska SeaLife Center, CS by the Durham Doctoral Studentship.

Availability of data and materials Not applicable.

\section{Ethics approval and consent to participate}

No original animal work was conducted for this effort. However, marine mammals are specially protected in most jurisdictions under a variety of national and international regulations, and all work on pinnipeds referenced here required prior approval by various regulatory bodies and by institutional ethics review boards.

Consent for publication

Not applicable.

\footnotetext{
${ }^{5}$ https://ioos.noaa.gov/ (retrieved 5/5/2019).

${ }^{6}$ https://atn.ioos.us/ (retrieved 5/5/2019).

7 http://www.meop.net/database/ (retrieved 5/5/2019).

8 https://www.movebank.org/ (retrieved 5/5/2019).
} 


\section{Competing interests}

The authors declare that they have no competing interests.

\section{Author details}

${ }^{1}$ Alaska SeaLife Center, 301 Railway Avenue, Seward, AK 99664-1329, USA. 2 Marine Mammal Institute, Oregon State University, Newport, OR 97365 USA. ${ }^{3}$ Marine Ecology and Telemetry Research, 2468 Camp McKenzie Trail NW, Seabeck, WA 98380, USA. ${ }^{4}$ Marine Mammal Laboratory, NOAA Alaska Fisheries Science Center, 7600 Sand Point Way NE, Seattle, WA 98115, USA. ${ }^{5}$ Dept. of Ecology and Evolutionary Biology, University of California Santa Cruz, Santa Cruz, CA 95060, USA. ${ }^{6}$ Sonoma State University, Rohnert Park, CA 94928, USA. ${ }^{7}$ Vancouver Aquarium, 845 Avison Way, Vancouver, BC V6G 3E2, Canada. ${ }^{8}$ Institute for Marine and Antarctic Studies, University of Tasmania, 20 Castray Esplanade, Battery Point, Hobart TAS 7004, Australia. ${ }^{9}$ School of Life Sciences, University of Nevada Las Vegas, 4505 Maryland Parkway, Las Vegas, NV 89154 USA. ${ }^{10}$ Sea Mammal Research Unit, Scottish Oceans Institute, University of St Andrews, St Andrews, Fife KY16 8LB, UK. ${ }^{11}$ The Marine Mammal Center, 2000 Bunker Rd, Sausalito, CA 95965, USA. ${ }^{12}$ Moss Landing Marine Laboratories, San Jose State University, 8272 Moss Landing Road, Moss Landing, CA 95039, USA. 13 IMOS Animal Satellite Tagging, Sydney Institute of Marine Science, 19 Chowder Bay Road, Mosman 2088, NSW, Australia. ${ }^{14}$ Department of Biosciences, South Road, Durham University, Durham DH1 3LE, UK. ${ }^{15}$ Marine Mammal Program, Oregon Department of Fish and Wildlife, 7118 NE Vandenberg Ave, Corvallis, OR 97330, USA. ${ }^{16}$ National Marine Mammal Foundation, 2240 Shelter Island Drive Suite 200, San Diego, CA 92106, USA. ${ }^{17}$ National Park Service, 3100 National Park Road, Juneau, AK 99801, USA.

Received: 17 May 2019 Accepted: 17 September 2019 Published online: 04 October 2019

\section{References}

1. Acquarone M, Born EW, Griffiths D, Knutsen L $\varnothing$, Wiig $\varnothing$, Gjertz I. Evaluation of etorphine reversed by diprenorphine for the immobilisation of free-ranging Atlantic walrus (Odobenus rosmarus rosmarus L.). NAMMCO Sci Publ. 2014:9:16.

2. Adachi T, Maresh JL, Robinson PW, Peteron SH, Costa DP, Naito Y, Watanabe YY, Takahashi A. The foraging benefits of being fat in a highly migratory marine mammal. Proc R Soc B. 2017;281:20142120.

3. Andrews RD, Jones DR, Williams JD, Thorson PH, Oliver GW, Costa DP, Le Boeuf BJ. Heart rates of northern elephant seals diving at sea and resting on the beach. J Exp Biol. 1997;200:2083-95.

4. Andrews RD, Baird RW, Calambokidis J, Goertz CEC, Gulland FMD, Heide-Jørgensen MP, Hooker SK, Johnson M, Mate B, Mitani Y, Nowacek DP, Owen K, Quakenbush LT, Raverty S, Robbins J, Schorr GS, Shpak OV, Townsend FI Jr, Uhart M, Wells RS, Zerbini AN (2007) Best practice guidelines for cetacean tagging. J Cetacean Res Manag (in press)

5. Aoki K, Watanabe YY, Crocker DE, Robinson PW, Biuw M, Costa DP, Miyazaki N, Fedak MA, Miller PJ. Northern elephant seals adjust gliding and stroking patterns with changes in buoyancy: validation of at-sea metrics of body density. J Exp Biol. 2011;214:2973-87.

6. Arthur B, Hindell M, Bester M, Trathan P, Jonsen I, Staniland I, Oosthuizen WC, Wege M, Lea M-A. Return customers: foraging site fidelity and the effect of environmental variability in wide-ranging Antarctic fur seals. PLOS ONE. 2015;10:e0120888.

7. Authier M, Péron C, Mante A, Vidal P, Grémillet D. Designing observational biologging studies to assess the causal effect of instrumentation. Methods Ecol Evol. 2013;4:802-10.

8. Baker JD, Johanos TC. Effects of research handling on the endangered Hawaiian monk seal. Mar Mamm Sci. 2002:18:500-12.

9. Bateson P. When to experiment on animals. New Sci. 1986;109:30-2.

10. Baylis AMM, Page B, Staniland I, Arnould JPY, McKenzie J. Taking the sting out of darting: risks, restraint drugs and procedures for the chemical restraint of Southern Hemisphere otariids. Mar Mamm Sci. 2015;31:322-44.

11. Boehlert GW, Costa DP, Crocker DE, Green P, O'Brien T, Levitus S, Le Boeuf BJ. Autonomous pinniped environmental samplers: using instrumented animals as oceanographic data collectors. J Atm Oceanic Techn. 2001;18:1882-93.
12. Boehme L, Lovell P, Biuw M, Roquet F, Nicholson J, Thorpe SE, Meredith MP, Fedak M. Technical note: animal-borne CTD-satellite relay data loggers for real-time oceanographic data collection. Ocean Sci. 2009;5:685-95.

13. Bornemann H, de Bruyn PJN, Reisinger RR, Kästner S, Márquez MEl, Mclntyre T, Bester MN, Plötz J. Tiletamine/zolazepam immobilization of adult post-moult southern elephant seal males. Polar Biol. 2013;36(11):1687-92.

14. Boyd IL. Selecting sampling frequency for measuring diving behavior. Mar Mamm Sci. 1993:9:424-30.

15. Boyd IL, McCafferty DJ, Walker TR. Variation in foraging effort by lactating Antarctic fur seals: response to simulated increased foraging costs. Behav Ecol Sociobiol. 1997:40:135-44.

16. Breed GA, Costa DP, Goebel ME, Robinson PW. Electronic tracking tag programming is critical to data collection for behavioral time-series analysis. Ecosphere. 2011;2:1-10.

17. Casper RM. Guidelines for the instrumentation of wild birds and mammals. Anim Behav. 2009;78:1477-83.

18. Castellini MA, Davis RW, Kooyman GL. Annual cycles of diving behavior and ecology of the Weddell Seal. In: Castellini MA, editor. Bulletin of the Scripps Institution of Oceanography. Berkeley: Univ of California Press; 1991.

19. Castellini MA, Kooyman GL, Ponganis PJ. Metabolic rates of freely diving Weddell seals: correlations with oxygen stores, swim velocity and diving duration. J Exp Biol. 1992;165:181-94.

20. Champagne CD, Houser DS, Costa DP, Crocker DE. The effects of handling and anesthetic agents on the stress response and carbohydrate metabolism in northern elephant seals. PLoS ONE. 2012:7(5):e38442.

21. Cooke SJ, Hinch SG, Wikelski M, Andrews RD, Kuchel LJ, Wolcott TG, Butler PJ. Biotelemetry: a mechanistic approach to ecology. Trends Ecol Evol. 2004;19:334-43.

22. Costa DP, Robinson PW, Arnould JP, Harrison AL, Simmons SE, Hassrick JL, Hoskins AJ, Kirkman SP, Oosthuizen H, Villegas-Amtmann S, Crocker DE. Accuracy of ARGOS locations of Pinnipeds at-sea estimated using Fastloc GPS. PLoS ONE. 2010;5:e8677.

23. Croxall JP, Everson I, Kooyman GL, Ricketts C, Davis RW. Fur seal diving behaviour in relation to vertical distribution of krill. J Anim Ecol. 1985;54:1-8.

24. Davis RW, Fuiman LA, Williams TM, Collier SO, Hagey WP, Kanatous SB, Kohin S, Horning M. Hunting Behavior of a marine mammal beneath the antarctic fast ice. Science. 1999;283:993-6.

25. Dickens MJ, Delahanty DJ, Romero LM. Stress and translocation: alterations in the stress physiology of translocated birds. Proc Royal Soc. 2009;B276:2051-6.

26. Donohue MJ, Costa DP, Goebel ME, Baker JD. The ontogeny of metabolic rate and thermoregulatory capabilities of northern fur seal, Callorhinus ursinus, pups in air and water. J Exp Biol. 2000:203(6):1003-16.

27. Engelhard GH, Baarspul ANJ, Broekman M, Creuwels JCS, Reijnders PJH. Human disturbance, nursing behaviour, and lactational pup growth in a declining southern elephant seal (Mirounga leonina) population. Can J Zool. 2002;80(11):1876-86.

28. Farmer MC. Setting up an ethics of ecosystem research structure based on the precautionary principle. ILAR J. 2013;54(1):58-62.

29. Fedak MA, Anderson SS, Curry MG. Attachment of a radio tag to the fur of seals. Notes from the Mammal Society. 1983:46:298-300.

30. Ferraro MS, Decker RR, Costa DP, Robinson PW, Houser DS, Crocker DE. Evaluating gain functions in foraging bouts using vertical excursions in northern elephant seals. Anim Behav. 2017;129:15-24.

31. Field IC, Harcourt RG, Boehme L, de Bruyn PJN, Charrassin JB, McMahon CR, Bester MN, Fedak MA, Hindell MA. Refining instrument attachment on phocid seals. Mar Mamm Sci. 2012;28:E325-32.

32. Fowler SL, Costa DP, Arnould JP, Gales NJ, Kuhn CE. Ontogeny of diving behaviour in the Australian sea lion: trails of adolescence in a late bloomer. J Anim Ecol. 2006;75:358-67.

33. Fregosi S, Klinck H, Horning M, Costa DP, Mann D, Sexton K, Hückstädt LA, Mellinger DK, Southall BL. An animal-borne active acoustic tag for minimally invasive behavioral response studies on marine mammals. Anim Biotelemetry. 2016:4:9.

34. Gales NJ, Mattlin RH. Fast, safe, field-portable gas anesthesia for otariids. Mar Mamm Sci. 1998;14(355):361. 
35. Gales NJ, Bowen WD, Johnston DW, Kovacs KM, Littnan CL, Perrin WF, Reynolds JE III, Thompson PM. Guidelines for the treatment of marine mammals in field research. Mar Mamm Sci. 2009;25:725-36.

36. Gallon S, Baillful F, Charrassin J-B, Guinet C, Bost C-A, Handrich Y, Hindell $\mathrm{M}$. Identifying foraging events in deep diving southern elephant seals, Mirounga leonina, using acceleration data loggers. Deep-Sea Res Part II: Topical Studies in Oceanography. 2013;88-89:14-22.

37. Gentry RL, Kooyman GL. Fur Seals: Maternal Strategies on Land and at Sea. Princeton: Princeton University Press; 1986

38. Greig DJ, Gulland FMD, Harvey JT, Lonergan M, Hall AJ. Harbor seal pup dispersal and individual morphology, hematology, and contaminant factors affecting survival. Mar Mamm Sci. 2018;35:187-209.

39. Guppy M, Hill RD, Schneider RC, Qvist J, Liggins GC, Zapol WM, Hochachka PW. Microcomputer-assisted metabolic studies of voluntary diving of Weddell seals. Am J Physiol. 1986;250(2):175-87.

40. Halsey LG. Relationships grow with time: a note of caution about energy expenditure-proxy correlations, focussing on accelerometry as an example. Funct Ecol. 2017;31:1176-83.

41. Haulena M. Otariid Seals. In: West G, Heard D, Caulkett N, editors. Zoo animal and wild life immobilization and anesthesia, vol. 2. Ames: Wiley; 2014. p. 661-72.

42. Hawkins P. Refinements in telemetry procedures Seventh report of the BVAAWF/FRAME/RSPCA/UFAW joint working group on refinement, part A. Lab Anim. 2003;37:261-99.

43. Hazekamp AAH, Mayer R, Osinga N. Flow simulation along a seal: the impact of an external device. Eur J Wildl Res. 2010;56:131-40.

44. Hazen EL, Maxwell SM, Bailey H, Bograd SJ, Hamann M, Gaspar P, Godley BJ, Shillinger GL. Ontogeny in marine tagging and tracking science: technologies and data gaps. Mar Ecol Prog Ser. 2012;457:221-40.

45. Heaslip SG, Hooker SK. Effect of animal-borne camera and flash on the diving behaviour of the female Antarctic fur seal (Arctocephalus gazella). Deep-Sea Res. 2008;1 (55):1179-92.

46. Heath RB, Calkins D, McAllister D, Taylor W, Spraker T. Telazol and isoflurane field anesthesia in free-ranging Steller's sea lions (Eumetopias jubatus). J Zoo Wildl Med. 1996;27:35-43.

47. Hill RD, Schneider RC, Liggins GC, Schuette AH, Elliott RL, Guppy M, Hochachka PW, Qvist J, Falke KJ, Zapol WM. Heart rate and body temperature during free diving of Weddell seals. Am J Physiol. 1987;253(2):344-51

48. Hindell MA, Pemberton D. Successful use of a translocation program to investigate diving behavior in a male Australian fur seal, Arctocephalus pusillus doriferus. Mar Mamm Sci. 1997;13:219-28.

49. Hindle AG, Horning M, Mellish JE. Estimating total body heat dissipation in air and water from skin surface heat flux telemetry in Weddell seals. Anim Biotelemetry. 2015;3:50.

50. Hooker SK, Biuw M, McConnell BJ, Miller PJO, Sparling CE. Bio-logging science: logging and relaying physical and biological data using animal-attached tags. Deep-Sea Res. 2007;2(54):177-82.

51. Hooker SK, Barychka T, Jessopp MJ, Staniland IJ. Images as proximity sensors: the incidence of conspecific foraging in Antarctic fur seals. Anim Biotelem. 2015:3:37.

52. Horning M, Haulena M, Tuomi PA, Mellish JE, Goertz CE, Woodie K, Berngartt RK, Johnson S, Shuert CR, Walker KA, Skinner JP, Boveng PL. Best practice recommendations for the use of fully implanted telemetry devices in pinnipeds. Anim Biotelem. 2017:5:13.

53. Hussey NE, Kessel ST, Aarestrup K, Cooke SJ, Cowley PD, Fisk AT, Harcourt RG, Holland KN, Iverson SJ, Kocik JF, Mills Flemming JE, Whoriskey FG. Aquatic animal telemetry: a panoramic window into the underwater world. Science. 2015;348(6240):1-10.

54. Iwata T, Sakamoto KQ Takahashi A, Edwards EWJ, Staniland IJ, Trathan PN, Naito Y. Using a mandible accelerometer to study fine-scale foraging behavior of free-ranging Antarctic fur seals. Mar Mamm Sci. 2012;28:345-57.

55. Jeanniard-du-Dot T, Holland K, Schorr GS, Vo D. Motes enhance data recovery from satellite-relayed biologgers and can facilitate collaborative research into marine habitat utilization. Anim Biotelem. 2017:5:17.

56. Katz H, Reisfeld L, Franco-Trecu V. Chemical immobilization protocols in free-ranging South American fur seal (Arctocephalus australis) and adult female South American sea lion (Otaria byronia). Mar Mamm Sci. 2019;35(1):327-35.
57. Khamas WA, Smodlaka H, Leach-Robinson J, Palmer L. Skin histology and its role in heat dissipation in three pinniped species. Acta Vet Scand. 2012;54(1):46.

58. Kooyman GL. Techniques used in measuring diving capacities of Weddell seals. Polar Rec. 1965;12:391-4.

59. Kooyman GL. Maximum diving capacities of the Weddell seal, Leptonychotes weddellii. Science. 1966:151:1553-4.

60. Kooyman GL, Wahrenbrock EA, Castellini MA, Davis RW, Sinnett EE. Aerobic and anaerobic metabolism during voluntary diving in Weddell seals: evidence of preferred pathways from blood chemistry and behavior. J Comp Physiol B. 1980;138:335-46.

61. Kooyman GL. Weddell Seal: consummate diver. Cambridge: Cambridge University Press; 1981. p. 148.

62. Kooyman GL, Castellini MA, Davis RW, Maue RA. Aerobic dive limits of immature Weddell seals. J Comp Physiol B. 1983;151:171-4.

63. Kooyman GL. Genesis and evolution of bio-logging devices: 1963-2002. Mem Natl Inst Polar Res. 2004;58:15-22.

64. Krause DJ, Goebel ME, Marshall GJ, Abernathy K. Summer diving and haul-out behavior of leopard seals (Hydrurga leptonyx) near mesopredator breeding colonies at Livingston Island, Antarctic Peninsula. Mar Mamm Sci. 2016;32:839-67.

65. Kuhn CE, Crocker DE, Tremblay Y, Costa DP. Time to eat: measurements of feeding behaviour in a large marine predator, the northern elephant seal Mirounga angustirostris. J Anim Ecol. 2009;78:513-23.

66. Ladds MA, Rosen DAS, Slip DJ, Harcourt RG. Proxies of energy expenditure for marine mammals: an experimental test of "the time trap". Sci Rep. 2017:7:1-10.

67. Lavigne DM. Pinniped thermoregulation: comments on the "Effects of cold on the evolution of pinniped breeding systems". Evolution. 1982;36(2):409-14.

68. LeBoeuf BJ, Costa DP, Huntley AC, Kooyman GL, Davis RW. Pattern and depth of dives in northern Elephant Seals, Mirounga-Angustirostris. J Zool. 1986;208:1-7.

69. Lian M, Johnson S, Gelatt T, O'Hara TM, Beckmen KB, Rea LD. Field anesthesia of juvenile Steller sea lions (Eumetopias jubatus) using inhalation anesthesia. Mar Mamm Sci. 2018;34:125-35.

70. Lidgard DC, Bowen WD, Jonsen ID, McConnell BJ, Lovell P, Webber DM, Stone T, Iverson SJ. Transmitting species-interaction data from animal-borne transceivers through Service Argos using Bluetooth communication. Methods Ecol Evol. 2014;5:864-71.

71. MacDonald DW, Amlaner CJ. A practical guide to radio tracking. In A handbook on biotelemetry and radio tracking. Oxford: Pergamon Press; 1980. p. 143-59.

72. Maresh JL, Adachi T, Takahashi A, Naito Y, Crocker DE, Horning M, Williams TM, Costa DP. Summing the strokes: energy economy in northern elephant seals during large-scale foraging migrations. Movem Ecol. 2015:3:22.

73. Maresh JL, Simmons SE, Crocker DE, McDonald BI, Williams TM, Costa DP. Free-swimming northern elephant seals have low field metabolic rates that are sensitive to an increased cost of transport. J Exp Biol. 2014:217:1485-95

74. McCafferty DJ, Currie J, Sparling CE. The effect of instrument attachment on the surface temperature of juvenile grey seals (Halichoerus grypus) as measured by infrared thermography. Deep-Sea Res II. 2007:54(3-4):424-36.

75. McConnell BJ, Beaton R, Bryant E, Hunter C, Lovell P, Hall A. Phoning home-A new GSM mobile phone telemetry system to collect markrecapture data. Mar Mamm Sci. 2004:20:274-83.

76. McDonald BI, Ponganis PJ. Lung collapse in the diving sea lion: hold the nitrogen and save the oxygen. Biol Lett. 2012;8:1047-9.

77. McHuron EA, Block BA, Costa DP. Movements and dive behavior of juvenile California sea lions from Año Nuevo Island. Mar Mamm Sci. 2018;34(1):238-49

78. McIntyre T. Trends in tagging of marine mammals: a review of marine mammal biologging studies. African J Mar Sci. 2014;36(4):409-22.

79. McKenzie J, Page B, Goldsworthy SD, Hindell MA. Behavioral responses of New Zealand fur seals (Arctophoca australis forsteri) to darting and the effectiveness of midazolam and tiletamine-zolazepam for remote chemical immobilization. Mar Mammal Sci. 2013;29(2):241-60.

80. McMahon CR, van den Hoff J, Burton HR. Handling intensity and the short- and long-term survival of Elephant Seals: 
addressing and quantifying research effects on wild animals. Ambio. 2005;34(6):426-9.

81. McMahon CR, Field IC, Bradshaw CJA, White GC, Hindell MA. Tracking and data-logging devices attached to elephant seals do not affect individual mass gain or survival. J Exp Mar Biol Ecol. 2008;360:71-7.

82. McMahon CR, Harcourt R, Bateson PP, Hindell MA. Animal welfare and decision making in wild life research. Biol Cons. 2012;153:254-6.

83. Meir JU, Champagne CD, Costa DP, Williams CL, Ponganis PJ. Extreme hypoxemic tolerance and blood oxygen depletion in diving elephant seals. Am J Physiol Regul Integr Comp Physiol. 2009;297(4):R927-39.

84. Meir JU, Robinson PW, Vilchis LI, Kooyman GL, Costa DP, Ponganis PJ. Blood oxygen depletion is independent of dive function in a deep diving vertebrate, the northern elephant seal. PLOS ONE. 2013;8(12):e83248.

85. Melin SR, Haulena M, Van Bonn W, Tennis MJ, Brown RF, Harris JD. Reversible immobilization of free-ranging adult male California sea lions (Zalophus californianus). Mar Mamm Sci. 2013;29(4):E529-36.

86. Mellish JE, Tuomi PA, Hindle AG, Horning M. Chemical immobilization of Weddell seals (Leptonychotes weddellii) by ketamine/midazolam combination. Vet Anesth Analg. 2010;37:123-31.

87. Mellish J, Hindle A, Skinner J, Horning M. Heat loss in air of an Antarctic marine mammal, the Weddell seal. J Comp Physiol B. 2015;185:143-52.

88. Muir SF, Barnes DKA, Reid K. Interactions between humans and leopard seals. Antarctic Sci. 2006;18:61-74.

89. Murray DL, Fuller MR. A critical review of the effects of marking on the biology of vertebrates. In: Boitani L, Fuller TK, editors. Research techniques in animal ecology, controversies and consequences. New York: Columbia University Press; 2000. p. 15-46.

90. Naito Y, Costa DP, Adachi T, Robinson PW, Fowler M, Takahashi A. Unravelling the mysteries of a mesopelagic diet: a large apex predator specializes on small prey. Funct Ecol. 2013:27:710-7.

91. National Research Council. 2011. Guide for the care and use of laboratory animals. 8th edition. Institute for laboratory animal research. Washington: National Academies Press; 2011.

92. Ølberg R-A, Kovacs KM, Bertelsen MF, Semenova V, Lydersen C. Short duration immobilization of Atlantic walrus (Odobenus rosmarus rosmarus) with etorphine, and reversal with naltrexone. J Zoo Wildl Med. 2017;48:972-8.

93. Oliver GW, Morris PA, Thorson PH, Le Boeuf BJ. Homing behavior of juvenile northern elephant seals. Mar Mamm Sci. 1998;14(2):245-56.

94. Paterson WD, Redman P, Hiby LA, Moss SEW, Hall AJ, Pomeroy P. Pup to adult photo-ID: evidence of pelage stability in gray seals. Mar Mamm Sci. 2013:29:537-41.

95. Ponganis PJ, McDonald BI, Tift MS, Gonzalez SC, DaValle B, Gliniecki RA, Stehman CC, Hauff N, Ruddick B, Howard R. Effects of inhalational anesthesia on blood gases and pH in California sea lions. Mar Mamm Sci. 2017:33:726-37.

96. Pussini N, Goebel ME. A safer protocol for field immobilization of leopard seals (Hydrurga leptonyx). Mar Mamm Sci. 2015;2015(31):1549-58.

97. Robinson PW, Costa DP, Crocker DE, Gallo-Reynoso JP, Champagne CD, Fowler MA, Goetsch C, Goetz KT, Hassrick UL, Huckstadt LA, Kuhn CE, Maresh JL, Maxwell SM, McDonald Bl, Peterson SH, Simmons SE, Teutschel NM, Villegas-Amtmann S, Yoda K. Foraging behavior and success of a mesopelagic predator in the Northeast Pacific Ocean: insights from a data-rich species, the northern elephant seal. PLoS ONE. 2012;7(5):e36728.

98. Rosen DAS, Gerlinsky C, Trites AW. Telemetry tags increase the costs of swimming in northern fur seals. Callorhinus ursinus. Mar Mamm Sci. 2018;34(2):385-402.

99. Russell WMS, Burch RL. The principles of humane experimental technique. London: Methuen; 1959.

100. Rust LB, Danil K, Melin SR, Wilkerson B. Accuracy and precision of age determination using growth layer groups for California sea lions (Zalophus californianus) with known ages. Mar Mamm Sci. 2019:000:1-14.

101. Sequeira A, Heupel M, Lea M-A, Eguiluz VM, Duarte C, Meekan M, Thums M, Calich H, Carmichael R, Costa D, Ferreira L, Fernandez-Garcia J, Harcourt R, Harrison A-L, Jonsen I, McMahon C, Sims D, Wilson R, Hays $\mathrm{G}$. The importance of sample size in marine megafauna tagging studies, Ecol Appl. 2019. https://doi.org/10.1002/eap.1947.

102. Seguel M, Paredes E, Paves H, Gottdenker NL. Capture-induced stress cardiomyopathy in South American fur seal pups (Arctophoca australis gracilis). Mar Mamm Sci. 2014;30(3):1149-56.
103. Shuert $C$, Horning M, Mellish J. The effect of novel research activities on long-term survival of temporarily Captive Steller Sea Lions (Eumetopias jubatus). PLoS ONE. 2015;10:e0141948.

104. Sikes RS, IACUC of the ASM. Guidelines of the American Society of Mammalogists for the use of wild mammals in research. J Mammal. 2016;92:235-53.

105. Sikes RS, Paul E, Beaupre SJ. Taxon-specific guidelines versus US Public Health Service Policy. Bioscience. 2012;62:830-4.

106. Silanikove $N$. Effects of heat stress on the welfare of extensively managed domestic ruminants. Livestock Prod Sci. 2000;67(1-2):1-18.

107. Soma M, Tsutsumi M. Biological telemetry using the Argos system. Mesogee. 1986;46:87-92.

108. Speakman JR. Body composition analysis of animals. A handbook of non-destructive methods. Cambridge: Cambridge Univ Press; 2001.

109. Spraker TR, Lander ME. Causes of mortality in northern fur seals (Callorhinus ursinus), ST Paul Island, Pribilof Islands, Alaska, 1986-2006. J Wildl Dis. 2010:46(2):450-73.

110. Steingass S, Horning M, Bishop A. Space use of Pacific harbor seals (Phoca vitulina richardii) from two haulout locations along the central Oregon coast. PloS ONE. 2019;14(7):e0219484.

111. Suzuki I, Sato K, Fahlman A, Naito Y, Miyazaki N, Trites AW. Drag, but not buoyancy, affects swim speed in captive Steller sea lions. Biol Open. 2014;3(5):379-86.

112. Tarasoff FJ, Fisher HD. Anatomy of the hind flippers of two species of seals with reference to thermoregulation. Can J Zool. 1970;48(4):821-9.

113. Tift MS, Huckstadt LA, McDonald BI, Thorson PH, Ponganis PJ. Flipper stroke rate and venous oxygen levels in free-ranging California sea lions. J Exp Biol. 2017:220:1533-40.

114. Treasure AM, Roquet F, Ansorge IJ, Bester MN, Boehme L, Bornemann H, Charrassin J-B, Chevallier D, Costa DP, Fedak MA, Guinet C, Hammill MO, Harcourt RG, Hindell MA, Kovacs KM, Lea M-A, Lovell P, Lowther AD, Lydersen C, Mclntyre T, McMahon CR, Muelbert MMC, Nicholls K, Picard B, Reverdin G, Trites AW, Williams GD, de Bruyn PJN. Marine mammals exploring the oceans pole to pole: a review of the MEOP consortium. Oceanography. 2017;30(2):132-8.

115. Twiss SD, Wright NC, Dunstone N, Redman P, Moss S, Pomeroy PP. Behavioral evidence of thermal stress from overheating in UK breeding gray seals. Mar Mamm Sci. 2002;18(2):455-68.

116. Waite JN, Trumble SJ, Burkanov VN, Andrews RD. Resource partitioning by sympatric Steller sea lions and northern fur seals as revealed by biochemical dietary analyses and satellite telemetry. J Exp Mar Biol Ecol. 2012;2012(416-417):41-54.

117. Walker BG, Boveng PL. Effects of time-depth recorders on maternal foraging and attendance behavior of Antarctic fur seals (Arctocephalus gazella). Can J Zool. 1995;73:1538-44.

118. Walker KA, Trites AW, Haulena M, Weary DM. A review of the effects of different marking and tagging techniques on marine mammals. Wildl Res. 2012;39:15-30.

119. Wallace MC, Curzer HJ. Moral problems and perspectives for ecological field research. ILAR J. 2013;54(1):3-4

120. Webb PM, Crocker DE, Blackwell SB, Costa DP, Le Boeuf BJ. Effects of buoyancy on the diving behavior of northern elephant seals. J Exp Biol. 1998;201:2349-58.

121. West G, Heard D, Caulkett N. Zoo animal and wild life immobilization and anesthesia. 2nd ed. Ames: Wiley; 2014.

122. White FN, Odell DK. Thermoregulatory behavior of the northern elephant seal, Mirounga angustirostris. J Mammal. 1971;52(4):758-74.

123. Williams TM, Fuiman LA, Horning M, Davis RW. The cost of foraging by a marine predator, the Weddell seal Leptonychotes weddellii: pricing by the stroke. J Exp Biol. 2004;207:973-82.

124. Willis $K$, Horning M. A novel approach to measuring heat flux in swimming animals. J Exp Mar Biol Ecol. 2005;315:147-62.

125. Wilson RP, Grant WS, Duffy DC. Recording devices on free-ranging marine animals: does measurement affect foraging performance? Ecology. 1986;67:1091-3.

126. Wilson RP, McMahon CR. Measuring devices on wild animals: what constitutes acceptable practice? Front Ecol Env. 2006:4:147-54.

\section{Publisher's Note}

Springer Nature remains neutral with regard to jurisdictional claims in published maps and institutional affiliations. 